\title{
BMJ Open Workplace violence against nurses in Chinese hospitals: a cross-sectional survey
}

\author{
Mingli Jiao, ${ }^{1}$ Ning Ning, ${ }^{2}$ Ye Li, ${ }^{1}$ Lijun Gao, ${ }^{2}$ Yu Cui, ${ }^{2}$ Hong Sun, ${ }^{3}$ Zheng Kang, ${ }^{2}$ \\ Libo Liang, ${ }^{3}$ Qunhong Wu, ${ }^{1}$ Yanhua $\mathrm{Hao}^{2}$
}

To cite: Jiao M, Ning N, Li Y, et al. Workplace violence against nurses in Chinese hospitals: a cross-sectional survey. BMJ Open 2015;5: e006719. doi:10.1136/ bmjopen-2014-006719

- Prepublication history for this paper is available online. To view these files please visit the journal online (http://dx.doi.org/10.1136/ bmjopen-2014-006719).

Received 24 September 2014 Revised 17 February 2015 Accepted 2 March 2015

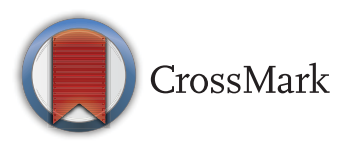

${ }^{1}$ Department of Health Policy and Hospital Management, School of Public Health, Harbin Medical University, Harbin, China

${ }^{2}$ Department of Social Medicine, School of Public Health, Harbin Medical University, Harbin, China ${ }^{3}$ Department of Medical Demography, School of Public Health, Harbin Medical University, Harbin, China

Correspondence to Dr Qunhong Wu; wuqunhong@163.com; Yanhua Hao;

hyhyjw@126.com

\section{ABSTRACT}

Objectives: To determine the prevalence of workplace violence that Chinese nurses have encountered, identify risk factors and provide a basis for future targeted interventions.

Setting: Heilongjiang, a province in northeast China. Methods: A cross-sectional survey.

Participants: A total of 588 nurses provided data. There were also in-depth interviews with 12 nurses, 7 hospital administrators and 6 health officials.

Results: A total of $7.8 \%$ of the nurses reported physically violent experiences and $71.9 \%$ reported nonphysically violent experiences in the preceding year. Perpetrators were patients or their relatives $(93.5 \%$ and $82 \%$, respectively), and $24 \%$ of nurses experienced non-physical violence that involved Yi Nao (gangs specifically targeting hospitals). Inexperienced nurses were more likely to report physical $(13.2 \%)$ or nonphysical $(89.5 \%)$ violence compared with experienced nurses. Graduate-level nurses were more likely to perceive and report non-physical violence (84.6\%). Nurses who worked rotating shifts were 3.668 times (95\% Cl 1.275 to 10.554$)$ more likely to experience physical violence, and 1.771 times (95\% Cl 1.123 to 2.792) more likely to experience non-physical violence compared with nurses who worked fixed day shifts. Higher anxiety levels about workplace violence and work types were associated with violence. Interviewees perceived financial burdens, unsatisfactory treatment outcomes and miscommunications as influencing factors for workplace violence.

Conclusions: Preplacement education should focus on high-risk groups to reduce workplace violence. Increased awareness from the public and policymakers is necessary to develop effective control strategies at individual, hospital and national levels.

\section{BACKGROUND}

In 2012, at the first affiliated hospital of Harbin Medical University (the hospital sampled in this study), a 17-year-old boy fatally stabbed a young intern who was uninvolved in his treatment. ${ }^{1}$ In late 2013 , several news events shocked China: an angry knife-

\section{Strengths and limitations of this study}

- The sample size of 588 respondents from seven hospitals in one province may limit the study's power.

- The retrospective method depends on respondents' memory; therefore, participants may suffer recall bias.

- Despite the limitations, this study provided the necessary evidence for building future interventions for health workers encountering potentially violent emergencies at the local level.

wielding patient violently attacked three nurses in a Changsha hospital; another patient who was unhappy with his nose operation stabbed a department head and two other doctors before being restrained by security guards; and two radiologists were beaten up by nine people after these people were unable to be examined immediately, which resulted in one radiologist being hospitalised. $^{2}$ A survey from the Chinese Hospital Association stated that violence against medical staff was rising; in 2012, there were a recorded 27.3 assaults on medical staff per hospital. Additionally, higher level hospitals suffered from more serious workplace violence (WPV) as these hospitals generally deal with more serious diseases and it is likely this could lead to higher stress levels among patients, family members and staff. ${ }^{2}$

Abuse of healthcare workers is a common problem, and while there is no general agreement between researchers on the definition, in this study, WPV was defined as "Incidents where staff are abused, threatened or assaulted in circumstances related to their work, including commuting to and from work, involving an explicit or implicit challenge to their safety, well-being or health". 3 This definition was adopted from the joint study of the International Labour Office 
(ILO)/International Council of Nurses (ICN)/WHO/ Public Services International (PSI), which was originally developed by the European Commission in Dublin in $1995{ }^{4}$ A report released by the ILO/ICN/WHO/PSI indicated that WPV is a universal issue faced by many occupations. ${ }^{5}$ WPV crosses all boundaries, and it could happen to anybody. ${ }^{6}$ It can be divided into physical violence and non-physical violence (threats, sexual harassment and verbal abuse). ${ }^{7}$

The prevalence of WPV varies by country and occupational setting. It is difficult to draw comparisons between studies, since different study designs and questionnaires were used. However, the following is clear: (1) visitors, intruders, patients and their family members, and co-workers, can be perpetrators of violence against healthcare professionals; (2) WPV can result directly in psychological and physical problems; (3) WPV can decrease job satisfaction and job performance; and (4) WPV can negatively affect patients' medical care. ${ }^{6-11}$

Through wide media coverage of extreme cases, mistrust and even hostility may grow, further destroying the trust-based doctor-patient relationship. Violence in China's hospitals has decreased the morale of healthcare workers, and has affected more long-term perceptions of the profession. A survey by the Chinese Medical Doctors' Association in 2011 revealed that only 7\% of doctors would like their own children to enter the medical profession; in 2002, this was $11 \% .^{12}$

The WPV study originated from mental health or emergency care settings. ${ }^{13}{ }^{14}$ In recent years, some studies have focused on WPV in general hospitals, but this has been minimal. Winstanley and Whittington ${ }^{15}$ estimated that WPV in general hospitals might be more serious than in mental healthcare settings. Meanwhile, hospital nurses report greater levels of assault compared with community nurses. ${ }^{16}$ Recently, more nurses have been the target of hospital violence, drawing grave concern from researchers and healthcare policymakers worldwide. ${ }^{17-21}$ However, in China, WPV remains underresearched, especially in northern China. ${ }^{92-24}$ In other countries, patients or their relatives usually perpetrate WPV. Except for several isolated fatal attacks reported in Turkey, Pakistan and the USA, serious injury and murder are very rare. However, the problem in China is unique because of the involvement of $\mathrm{Yi} \mathrm{Nao,} \mathrm{which} \mathrm{is} \mathrm{literally}$ defined as 'healthcare disturbance'. A 2006 survey of 270 tertiary hospitals reported that over $73 \%$ of the participating hospitals had experienced Yi Nao. ${ }^{1}$ Hesketh and Wu described $\mathrm{Yi} \mathrm{Nao}$ as gangs consisting "largely of unemployed people with a designated leader. They threaten and assault hospital personnel, damage facilities and equipment, and prevent the normal activities of the hospital." More broadly, Yi Nao describes any medical or hospital disturbance created by a group of people-such as patients, patients' families, relatives, or Yi Nao gang members hired by patients or their families-who gather at hospitals that are involved in disputes with patients for actual or perceived medical malpractice. The aim of Yi
Nao is to force the hospital to reduce costs or to obtain compensation from hospitals. When financial benefit becomes their main target, they use extreme acts or criminal behaviours in a manner that does not incite physical violence or attract punishment under the law, usually by threatening or abusing health workers verbally, to pressure hospitals to accept their demands.

This study has three objectives: (1) identify the prevalence and severity level of WPV against nurses in general hospitals in Heilongjiang Province, China; (2) investigate the perpetrators of the violence and (3) identify the risk factors contributing to China's WPV.

\section{METHODS}

A retrospective cross-sectional survey was conducted in Heilongjiang Province, China. Heilongjiang has a population of 38.1 million with 69 tertiary hospitals scattered across 13 cities. Owing to the time and resource limitations of this study, seven hospitals were purposively selected to represent different areas (east, middle and west) of the province; all seven responded. As most tertiary hospitals are located in the largest city-the capital, Harbin-we selected four hospitals in Harbin (middle area). Another two hospitals were selected in Qiqihar (the second largest city; west area) and one hospital was selected in Jiamusi (east area).

From July to September 2013, we randomly selected 100 registered nurses from various departments of the seven chosen hospitals. We first obtained a list of all nurses from the human resources departments of the hospitals and numbered the list; then we used Stata to generate a list of 100 from each hospital. The nurses were from a variety of departments-internal medicine, surgery, gynaecology, obstetrics, paediatrics, and the intensive care unit (ICU) and emergency room (ER) and different shift types (rotating shift and fixed day shift). The department managers from the seven chosen hospitals also assisted. After they consented to participate, the nurses were given a questionnaire, which they were asked to complete and return anonymously. To ensure anonymity, envelopes and a box were provided in the manager's office and no names or other identifiers were required. The boxes and questionnaires were the responsibility of one of the authors. Using this procedure, we obtained 588 valid questionnaires (response rate: $84 \%)$.

\section{QUESTIONNAIRE}

The questionnaire used to measure WPV was developed in 2003 by the ILO/ICN/WHO/PSI joint programme. ${ }^{25}$ We formally obtained documented permission to use the questionnaire from the ILO and WHO and then invited 17 healthcare-related experts from all over China to evaluate the content validity, including its suitability for use in Chinese culture, and the appropriateness of the translation. They recommended adding Yi Nao-related non-physical violence items to the original questionnaire. 
The 2-week test-retest reliability (0.87) was assessed using a group of 37 healthcare workers at five of the surveyed hospitals. The questionnaire was then back-translated to English to verify the accuracy of the Mandarin version.

The questionnaire has four sections: (1) demographic and workplace data, including a question about anxiety levels regarding WPV, which was measured on a scale from 1 (not at all) to 5 (extremely high); (2) questions about physical violence experiences within the preceding year; (3) non-physical violence, including Yi Nao-related non-physical violence (based on expert panel recommendations), within the preceding year; and (4) three open-ended questions to clarify respondents' opinions on WPV. To evaluate the results of physical and non-physical violence, a post-traumatic stress disorder (PTSD) scale containing four items (rehearsal, avoidance, hyperarousal and effort) was used to ask victims to indicate how much they were bothered by the incidents, with options ranging from 1 (not at all) to 5 (extremely). These items include "persistent re-experiencing of the traumatic event, such as thoughts, images, dreams, or percepts, persistent avoidance of stimuli associated with the trauma, numbing of general responsiveness, persistent symptoms of increased arousal, such as difficulty in concentrating and disturbances causing clinically significant distress or impairment in functioning." ${ }^{26} 27$ The diagnostic criteria are defined in the Diagnostic and Statistical Manual of Mental Disorders (DSM)-IV. ${ }^{27}$

\section{IN-DEPTH INTERVIEWS}

Twenty-five interviewees were purposively selected based on their roles and experience with WPV. The interviews were digitally recorded, transcribed and thematically coded. The final sample size was determined by saturation of information. Altogether, 12 nurses who reported WPV experiences, seven hospital administrators and six health officials completed the interviews.

\section{DATA ANALYSIS}

Demographic characteristics and the consequences of reported events were descriptively analysed. Univariate logistic regression analysis was used to evaluate the association between the characteristics of individual demographics and workplaces, and exposure to WPV. Significant factors were subsequently modelled in multivariate logistic regression analyses to estimate the OR of nurses' WPV experience. CIs for the ORs were calculated. IBM SPSS Statistics V.19.0 was used for analysis. Statistical significance was defined as $\mathrm{p}<0.05$.

The interviews were conducted, audio-recorded and transcribed verbatim by a trained interviewer (LL). The interview data were analysed thematically. The coding framework was developed inductively from the data by a researcher with substantial experience in qualitative research $(\mathrm{NN})$. The coding process was supervised by QW and double-checked by YH. The initial coding used open coding (codes derived directly from the data) and theoretical coding. The initial codes were then refined to produce a smaller set of themes. The coding framework was subject to continuing iterative revision during the analysis.

\section{ETHICAL CONSIDERATIONS}

Before the interviews, approval was obtained from each study hospital. All participants gave their informed content to participate.

\section{RESULTS}

\section{Demographic and professional characteristics}

Table 1 describes the demographic and professional characteristics of the surveyed nurses. A total of $41 \%$ of the 588 nurses were aged from 26 to 35 years $(n=241)$.

\begin{tabular}{|c|c|c|}
\hline Characteristic & $\mathbf{n}$ & Per cent \\
\hline \multicolumn{3}{|l|}{ Gender } \\
\hline Male & 26 & 4.4 \\
\hline Female & 562 & 95.6 \\
\hline \multicolumn{3}{|l|}{ Age groups (years of age) } \\
\hline$\leq 25$ & 163 & 27.7 \\
\hline $26-35$ & 241 & 41.0 \\
\hline$>35$ & 184 & 31.3 \\
\hline \multicolumn{3}{|l|}{ Years of experience } \\
\hline$\leq 5$ & 190 & 32.3 \\
\hline $6-10$ & 145 & 24.7 \\
\hline $11-15$ & 78 & 13.3 \\
\hline $16-20$ & 52 & 8.8 \\
\hline$\geq 21$ & 123 & 20.9 \\
\hline \multicolumn{3}{|l|}{ Marital status } \\
\hline $\begin{array}{l}\text { Single (never married, } \\
\text { divorced or widowed) }\end{array}$ & 248 & 42.2 \\
\hline Married & 340 & 57.8 \\
\hline Level of education & & 70.7 \\
\hline High school or less & 7 & 1.2 \\
\hline Vocational school & 165 & 28.1 \\
\hline Community college & 300 & 51.0 \\
\hline Undergraduate & 103 & 17.5 \\
\hline Graduate & 13 & 2.2 \\
\hline \multicolumn{3}{|l|}{ Work in shifts } \\
\hline Yes & 384 & 65.3 \\
\hline No & 204 & 34.7 \\
\hline \multicolumn{3}{|l|}{ Department } \\
\hline ER & 25 & 4.3 \\
\hline ICU & 24 & 4.1 \\
\hline Clinical wards & 490 & 83.3 \\
\hline Others & 49 & 8.3 \\
\hline \multicolumn{3}{|l|}{ Anxiety level } \\
\hline Extremely high & 244 & 41.5 \\
\hline High & 81 & 13.8 \\
\hline Moderate & 176 & 29.9 \\
\hline Low & 51 & 8.7 \\
\hline Zero & 36 & 6.1 \\
\hline
\end{tabular}


Table 2 Incidence of exposure to workplace violence $(\mathrm{N}=588)$

\begin{tabular}{|c|c|c|c|c|c|c|c|c|c|c|c|c|}
\hline \multirow{3}{*}{$\begin{array}{l}\text { Exposure to } \\
\text { violence }\end{array}$} & \multirow{2}{*}{\multicolumn{2}{|c|}{$\begin{array}{l}\text { Physical } \\
\text { violence } \\
\end{array}$}} & \multicolumn{10}{|c|}{ Non-physical } \\
\hline & & & \multicolumn{2}{|c|}{ Verbal abuse } & \multicolumn{2}{|c|}{ Yi Nao } & \multicolumn{2}{|c|}{ Threats } & \multicolumn{2}{|c|}{$\begin{array}{l}\text { Sexual } \\
\text { harassment }\end{array}$} & \multicolumn{2}{|c|}{$\begin{array}{l}\text { Total } \\
\text { non-physical }\end{array}$} \\
\hline & $\mathrm{n}$ & Per cent & $\mathrm{n}$ & Per cent & $\mathrm{n}$ & Per cent & $\overline{\mathbf{n}}$ & Per cent & $\mathrm{n}$ & Per cent & $\bar{n}$ & Per cent \\
\hline Yes & 46 & 7.8 & 405 & 68.9 & 141 & 24.0 & 209 & 35.5 & 75 & 12.8 & 423 & 71.9 \\
\hline No & 542 & 92.2 & 183 & 31.1 & 447 & 76.0 & 379 & 64.5 & 513 & 87.2 & 165 & 28.1 \\
\hline
\end{tabular}

Most respondents were female $(\mathrm{n}=562 ; 95.6 \%)$, married $(\mathrm{n}=340 ; 57.8 \%)$ and reported working rotating shifts $(\mathrm{n}=384 ; 65.3 \%)$. In the sample hospitals, nurses undertaking shift work can be divided into fixed day shift and rotating shift groups. Most clinical nurses worked eighthour shifts; head nurses or nurses involved in infants' breastfeeding schedules worked fixed day shifts, while some hospitals extended this priority level until the children were 4 years of age. There were 190 respondents with 1-5 years of nursing experience $(32.3 \%)$. About $41.5 \%$ reported an extremely high level of anxiety regarding WPV.

\section{Frequency of physical and non-physical violence}

In the preceding year, $7.8 \% \quad(\mathrm{n}=46)$ of nurses reported experiencing physical violence and $71.9 \% \quad(n=423)$ had experienced non-physical violence. In all non-physical cases, $68.9 \%$ of nurses said they experienced verbal aggression once or more, $24 \%$ experienced Yi Nao disturbances, $35.5 \%$ experienced threats and $12.8 \%$ experienced sexual harassment (table 2).

Over half the nurses who were physically attacked $(54.3 \%)$ believed the incidents were preventable, meaning that the WPV that they encountered could have been avoided if suitable measures were implemented; one-third of nurses (30.7\%) who had suffered non-physical violence believed the incidents were preventable. Nurses who had experienced physical violence comprised $34.8 \%$. Of the respondents who had experienced non-physical violence, $46.8 \%$ reported that investigations had been undertaken regarding the causes of the incidents, and that their managers or supervisors had conducted these inquiries. Regardless of whether it was physical $(93.5 \%)$ or non-physical violence $(82 \%)$, most perpetrators were patients, however, in some cases, co-workers $(1.6 \%)$ or managers/supervisors $(1.9 \%)$ were perpetrators of non-physical violence. Victims of physical violence $(39.1 \%)$ and non-physical violence $(13 \%)$ suffered from noteworthy PTSD symptoms (table 3 ).

Results showed that nurses who work in the ER run the greatest risk of physical violence. Of those who worked in the ER, 20\% reported physical aggression; this was followed by respondents with fewer than 5 years' work experience $(13.2 \%)$, nurses reporting extremely high levels of anxiety regarding WPV (11.9\%) and rotating shift workers $(10.7 \%)$. There were no significant differences in risk profiles between men and women, ages, or educational groups (table 4).

Higher risk of non-physical violence was related to being single, younger, having higher levels of education, rotating shift work and higher levels of anxiety about WPV. A total of $80.4 \%$ of nurses under 25 years of age reported non-physical violence, which decreased gradually with age. Non-physical violence was reported more frequently in the graduate degree group $(84.6 \%)$ compared with the lower education groups, such as undergraduate $(76.7 \%)$, community school $(74.3 \%)$, vocational school $(66.1 \%)$ and high school or lower $(14.3 \%)$. Rotating shift workers $(79.4 \%)$ were exposed to more non-physical violence compared to fixed day shift workers $(57.8 \%)$. Compared with physical violence, non-physical violence when working in ERs or ICUs was not found to be higher. For physical or non-physical violence, nurses with high anxiety about WPV were more likely to be victims (table 4).

\section{Factors associated with WPV}

Multiple logistic regression analysis indicated a reduced risk of physical violence for nurses with over 5 years' work experience, lower anxiety levels about WPV and no experience in the ER. An increased likelihood of being

Table 3 Frequency distributions (in \%) for physical and non-physical violence experienced by 588 nurses in the preceding year

\begin{tabular}{lll}
\hline Type of violence & $\begin{array}{l}\text { Physical } \\
\text { violence }\end{array}$ & $\begin{array}{l}\text { Non-physical } \\
\text { violence }\end{array}$ \\
\hline $\mathrm{N}$ & 46 & 423 \\
Incident is preventable & 54.3 & 30.7 \\
$\begin{array}{l}\text { Action taken to investigate } \\
\text { Who is the assailant? }\end{array}$ & 34.8 & 46.8 \\
$\quad$ Patient/client & 93.5 & 82.0 \\
$\quad \begin{array}{l}\text { Patients' relatives or } \\
\text { visitors }\end{array}$ & 6.0 & 14.0 \\
$\quad$ Staff member & & \\
$\quad$ Management/supervisor & 0.0 & 1.6 \\
PTSD score* & 0.0 & 1.9 \\
$\quad<10$ & 21.7 & 42.1 \\
$\quad$ 10-14 & 30.4 & 36.6 \\
$>14$ & 39.1 & 13.0 \\
\hline
\end{tabular}

*The sum may be less than $100 \%$ because of missing data. PTSD, post-traumatic stress disorder. 
Table 4 Characteristics and frequency distributions (in \%) for physical and non-physical violence

\begin{tabular}{|c|c|c|c|c|c|c|c|c|}
\hline & \multicolumn{4}{|c|}{ Physical violence } & \multicolumn{4}{|c|}{ Non-physical violence* } \\
\hline & $\mathbf{n}$ & Per cent & $\chi^{2}$ & $p$ Value & $\mathrm{n}$ & Per cent & $\chi^{2}$ & p Value \\
\hline \multicolumn{9}{|l|}{ Gender } \\
\hline Male & 2 & 7.7 & \multirow[t]{2}{*}{0.001} & \multirow[t]{2}{*}{0.980} & 20 & 76.9 & \multirow[t]{2}{*}{0.335} & \multirow[t]{2}{*}{0.563} \\
\hline Female & 44 & 7.8 & & & 403 & 71.7 & & \\
\hline \multicolumn{9}{|l|}{ Marital status } \\
\hline $\begin{array}{l}\text { Single (never married, } \\
\text { divorced or widowed) }\end{array}$ & 22 & 8.9 & \multirow[t]{2}{*}{0.653} & \multirow[t]{2}{*}{0.419} & 201 & 81.0 & \multirow[t]{2}{*}{17.631} & \multirow[t]{2}{*}{0.000} \\
\hline Married & 24 & 7.1 & & & 222 & 65.3 & & \\
\hline \multicolumn{9}{|l|}{ Age groups } \\
\hline$\leq 25$ & 13 & 8.0 & \multirow{3}{*}{1.443} & \multirow[t]{3}{*}{0.486} & 131 & 80.4 & \multirow{3}{*}{29.719} & \multirow[t]{3}{*}{0.000} \\
\hline $26-35$ & 22 & 9.1 & & & 187 & 77.6 & & \\
\hline$>35$ & 11 & 6.0 & & & 105 & 57.1 & & \\
\hline \multicolumn{9}{|l|}{ Level of education } \\
\hline High school or less & 1 & 14.3 & \multirow[t]{5}{*}{4.560} & \multirow[t]{5}{*}{0.335} & 1 & 14.3 & \multirow[t]{5}{*}{17.393} & \multirow[t]{5}{*}{0.002} \\
\hline Vocational school & 8 & 4.8 & & & 109 & 66.1 & & \\
\hline Community college & 28 & 9.3 & & & 223 & 74.3 & & \\
\hline Undergraduate & 7 & 6.8 & & & 79 & 76.7 & & \\
\hline Graduate & 2 & 15.4 & & & 11 & 84.6 & & \\
\hline \multicolumn{9}{|l|}{ Years of experience } \\
\hline$\leq 5$ & 25 & 13.2 & \multirow[t]{5}{*}{13.000} & \multirow[t]{5}{*}{0.011} & 170 & 89.5 & \multirow[t]{5}{*}{67.061} & 0.000 \\
\hline $6-10$ & 11 & 7.6 & & & 101 & 69.7 & & \\
\hline $11-15$ & 4 & 5.1 & & & 55 & 70.5 & & \\
\hline $16-20$ & 2 & 3.8 & & & 39 & 75.0 & & \\
\hline$\geq 21$ & 4 & 3.3 & & & 58 & 47.2 & & \\
\hline Work in shifts & & & & & & & & \\
\hline Yes & 41 & 10.7 & 12.502 & 0.000 & 305 & 79.4 & 30.745 & 0.000 \\
\hline No & 5 & 2.5 & & & 118 & 57.8 & & \\
\hline Department & & & & & & & & \\
\hline ER & 5 & 20.0 & 8.471 & 0.037 & 20 & 80.0 & 1.431 & 0.698 \\
\hline $\mathrm{ICU}$ & 4 & 16.7 & & & 18 & 75.0 & & \\
\hline Clinical wards & 34 & 6.9 & & & 352 & 71.8 & & \\
\hline Other workers & 3 & 6.1 & & & 33 & 67.3 & & \\
\hline Anxiety level & & & & & & & & \\
\hline Extremely high & 29 & 11.9 & 9.942 & 0.041 & 186 & 76.2 & 21.311 & 0.000 \\
\hline High & 3 & 3.7 & & & 66 & 81.5 & & \\
\hline Moderate & 10 & 5.7 & & & 124 & 70.5 & & \\
\hline Low & 2 & 3.9 & & & 30 & 58.8 & & \\
\hline Zero & 2 & 5.6 & & & 17 & 47.2 & & \\
\hline
\end{tabular}

non-physically abused was predicted among nurses with higher levels of anxiety, while having over 5 years' experience reduced the risk of being abused. Work type did not result in any difference in the likelihood of nonphysical violence. In contrast, rotating shift nurses were 3.668 (95\% CI 1.275 to 10.554 ) times more likely to experience physical violence and 1.771 times $(95 \%$ CI 1.123 to 2.792$)$ more likely to experience non-physical violence compared with nurses who worked fixed day shifts (table 5).

\section{Reasons for WPV}

The top three contributing factors for WPV outlined by the nurses were as follows: financial burdens $(n=401$, $68.2 \%)$, unsatisfactory treatment outcomes $(\mathrm{n}=393$, $66.8 \%)$ and miscommunications $(\mathrm{n}=347,59 \%)$. These findings were confirmed through the interviews with nurses, hospital administrators and health officials.

Qualitative analysis complemented the quantitative analysis by investigating the determinants of WPV. Hospital administrators noted that hospitals now receive very limited financial support from the government, forcing the hospitals to generate more income from the market to cover costs. Additionally, high co-payment rates that are required by medical insurance schemes make medical expenses a heavy burden for patients and their families. Patients also often rush to secondary and tertiary hospitals with unrealistic expectations, overcrowding tertiary hospitals. Regarding the media environment, many nurses and hospital administrators indicated that extensive publicity of various medical errors, disputes or scandals through different forms of 


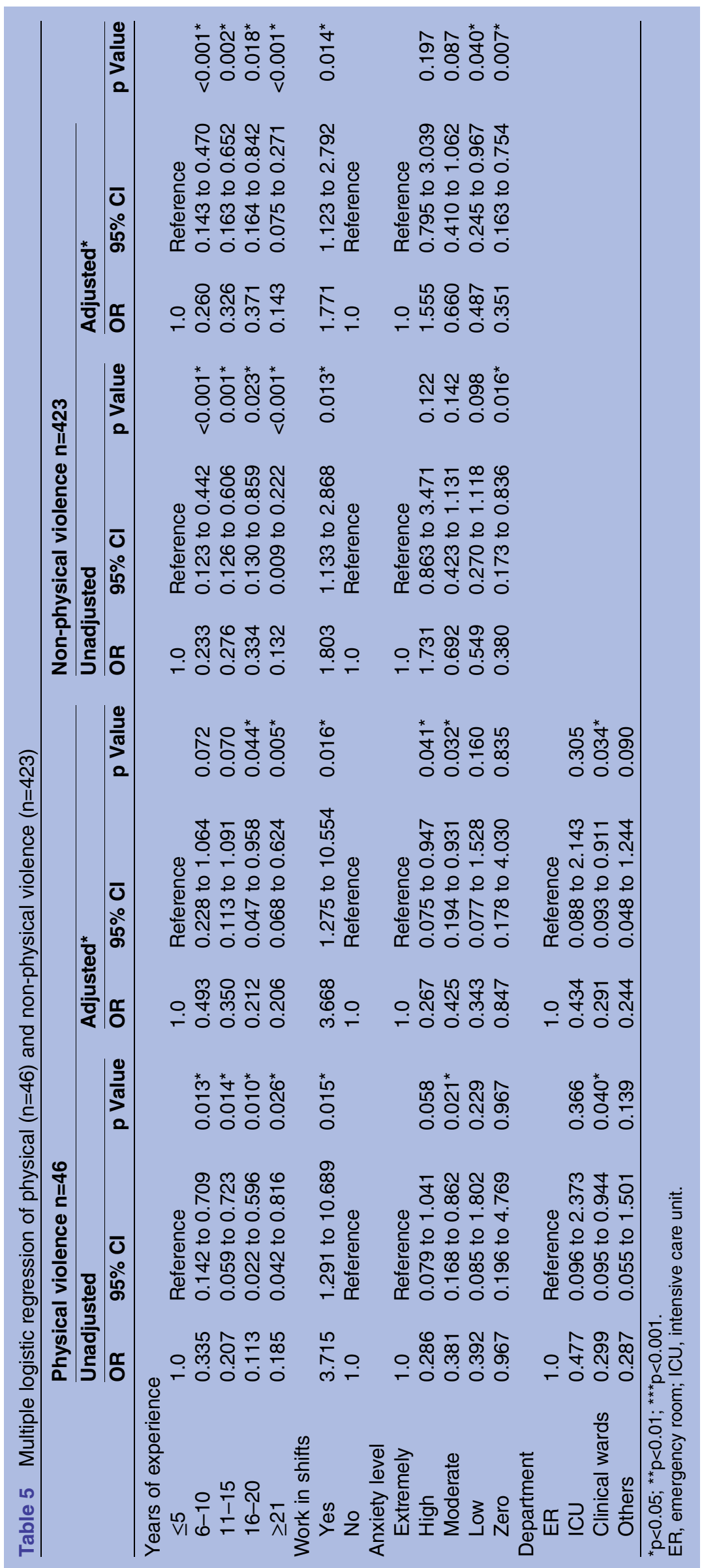


mass media-such as TV, newspapers and the internetplay an important role in provoking distrust in doctors, nurses and hospitals, especially misleading reports on health professionals cheating patients. This negative publicity makes many patients believe that doctors and hospitals conspire to increase charges by prescribing unnecessary, expensive medicines or by providing expensive examinations and other forms of treatment.

Hospital managers noted that patients are now frequently referred to as clients, users, consumers or customers, implying that people in need of health services should take a consumerist role and that they should have high expectations regarding medical results. If the desired results do not materialise, the patients or their families tend to demonstrate their dissatisfaction towards the healthcare professionals with whom they are in direct contact-in particular, nurses.

Healthcare managers are stressed, as patients and their families usually have high expectations for medical treatment and a tendency to believe that the symptoms of diseases can be controlled totally or relieved in hospitals. This results in little tolerance for medical treatment failure. Additionally, other macrosystem factors-such as poor government investment in hospitals and the unsatisfactory role of medical insurance-also contribute to increasing tensions between doctors and patients.

In addition, health officials stressed that institutional factors within hospitals contribute to WPV, such as sluggish procedures, which result in long waiting times. Additionally, poor communication between medical providers (including staff) and patients often leads to WPV. Effective mechanisms to identify and check potential medical risks within a hospital's quality management system are also lacking. Also, individual factors from patients and nurses contribute to WPV. The interviewed health managers believe that the combination of these factors causes dissatisfaction among patients and relatives with their doctors and nurses.

Nurses also noted that heavy workloads and long waiting times are related to WPV. One nurse is responsible for an average of 10 patients; however, this number can rise to more than 1:15, and sometimes nurses must continue to work even when they themselves are unwell. It is common in large hospitals to see nurses work nearly 10 or $11 \mathrm{~h}$ a day. When patients' requests cannot be met on time, nurses become the object of frustration, discontent and anger.

\section{DISCUSSION}

Our study found that violence and aggression towards nurses is frequent, with non-physical $(71.9 \%)$ violence being more prevalent compared with physical violence $(7.8 \%)$. This shows that China is among those countries with relatively high WPV levels. ${ }^{28-31}$ Prevalence of nonphysical violence shows a differing tendency by education level: $84.6 \%$ of nurses with graduate degrees and $76.7 \%$ of nurses with undergraduate degrees report such violence. This finding is unexpected and inconsistent with other studies, which suggest that a lower level of education is associated with violence. ${ }^{82-35}$ There are two possible reasons: (1) in China, nurses with higher levels of education are usually assigned a job with higher responsibility, thereby exposing them to more situations in which they must handle difficult cases and medical disputes, which might result in WPV; (2) nurses with graduate-level education tend to have stronger rights-protection awareness and self-confidence, do not consider assaults as 'part of the job', and do not worry that reporting assaults will lower their external evaluation. Conversely, nurses with a lower level of education might under-report their experiences with violence because they take this violence as an 'expected' part of their job and consider being a victim of violence to be shameful. ${ }^{36}$ From Hoff's ${ }^{37}$ study, we know that the stigma of victimisation-shame, threat of further violence, isolation and fear of judgement-often prevents victims from reporting violent behaviour. Additionally, nurses with higher levels of education might have better academic training but little workplace experience compared with their counterparts with lower levels of education, which might mean that they have more exposure to cases that they do not have the skills to manage.

This study found that patients perpetrated $93.5 \%$ of physical violence and $82 \%$ of non-physical violence incidents; however, other health workers perpetrated 3.5\% of non-physical violence on nurses, which is consistent with the results of studies in other countries. ${ }^{26} 3335$ 38-41 Violence perpetrated by other healthcare workers is called 'internal violence', and can be divided into two distinct patterns: lateral and vertical. Abusive behaviour between coworkers of similar status, such as nurse-to-nurse, is lateral violence. Vertical violence refers to behaviour conducted by senior colleagues towards a subordinate. ${ }^{42}$ In our study, $1.6 \%$ of internal violence was lateral-perpetrated by staff members-and $1.9 \%$ was vertical-perpetrated by senior nurses, supervisors and doctors. This finding is particularly alarming and requires us to pay more attention to internal violence. To prevent this kind of violent behaviour, traditional measures—such as development of personal safety skills and de-escalation-may not be sufficient.

Our study found that $24 \%$ of respondents reported suffering non-physical violence in relation to Yi Nao. Owing to the lack of an effective medical disputehandling system and unsatisfactory social support atmosphere, some patients and their families resort to violence or criminal acts by assaulting staff or destroying hospital facilities to coerce hospitals into an agreement via blackmail. Their goal is to force hospitals into providing them with extraordinary compensations for medical disputes. Another study found that of the 124 cases of violence reported on their website, 37 involved Yi Nao. ${ }^{1}$

Our multivariate logistic results indicate that work types, shift-work status, anxiety levels about WPV and nursing experience groups influence the risk of 
exposure to physical violence. Our study found that nurses working in an ER have the highest risk of exposure to physical violence, which is consistent with findings in other countries. ${ }^{13}$ Inexperienced nurses are more vulnerable to the risk of WPV than their more experienced colleagues are. The risk level decreases with nursing experience for all types of violence. Nurses who work in rotating shifts are 3.668 times more likely to experience physical violence and 1.771 times more likely to experience non-physical violence compared with those who work fixed day shifts. This finding corroborates with previous studies, which noted that working night shifts was considered a high risk of being exposed to violence with nurses more likely to report physical and non-physical abuse. ${ }^{32} 3843$

An important finding in our study is that higher anxiety levels about WPV are associated with an increased risk of physical or non-physical violence. This is consistent with a recent study that found that a higher prevalence of physical violence exists among healthcare workers with higher levels of anxiety. ${ }^{26}$ The cyclical model by Whittington and Wykes ${ }^{44}$ suggests that stress induced by exposure to violence leads to an adoption of behaviours that in turn increase the likelihood of a reoccurrence of violence. Moreover, for non-physical violence, higher risk is associated with those who are single, younger, have high levels of education and who perform rotating shift work. The relationship between high-level anxiety and violence needs further examination and future studies should consider all of the aforementioned factors.

Other than the risk factors for staff, another predominantly perceived reason for WPV against nurses is related to financial burden, which might be a unique finding in this study compared with research findings in other, more politically stable countries. Such instability and poor financial status have been shown to contribute to the high prevalence of violence against healthcare workers. ${ }^{35}$ China's health insurance coverage has increased from $15 \%$ in 2000 to $96 \%$ in 2011, but the co-payment rates of enrolees of different schemes vary from $45 \%$ to $70 \%{ }^{45}$ In this situation, it is difficult to reduce the medical care burdens of patients and their families.

Nevertheless, several factors may play a contributory role to WPV against health workers, including unsatisfactory treatment outcomes, miscommunications and healthcare staff characteristics (lack of sensitivity/courtesy/respect/tact). Moreover, some cultural or social factors may contribute to violence against nurses. ${ }^{46}$ Traditionally, Chinese people tend to seek a high level of care even for minor, self-limiting conditions. Because they do not need to obtain referrals from primary care physicians, patients often visit secondary and tertiary hospitals with unrealistic expectations. ${ }^{1}$ Overloaded facilities and overworked healthcare staff lead to rushed, 'indifferent' (spending only a few minutes with each patient and lacking effective communication) and disrespectful treatment of patients, which might be the major causes of doctor-patient tension. Additionally, negative media reports create public distrust and anger against medical professionals; the media, in generating spectacle, tend to report on medical negligence, health system failures and bribe-taking cases. ${ }^{1}{ }^{47-49}$

This study has several limitations. First, data were collected retrospectively; this method depends on the ability of participants to recall events that occurred in the 12 months before our study, potentially resulting in recall bias. Second, the study's time and resource restrictions confined the investigation to seven tertiary public hospitals in Heilongjiang Province; therefore, our results may not be generalisable to the entire hospital system in Heilongjiang. However, the exploration of risk factors might be valuable for the control of WPV in general hospitals.

Ending violence against nurses is dependent on efforts from various levels. Preplacement education should focus on at-risk groups to reduce WPV at an institutional level, while national strategies should also be developed to respond to WPV. If government investment in hospitals is increased, a redesign of health insurance could potentially decrease the burden. Strong actions against the criminal offences of $\mathrm{Yi} \mathrm{NaO}$ in accordance with the law and regulations can help safeguard health worker security. A better system of legal redress would also help reduce acts of retributive violence and reliance on Yi Nao in dealing with disputes and obtaining compensation. Additionally, news media should encourage the public to rebuild the image of the healthcare provider as attractive, respected, rewarding and safe, to protect the healthcare workers of today and tomorrow.

Acknowledgements The authors thank all the nurses who provided the information necessary for completion of the study. They also acknowledge $\mathrm{Dr}$ David $\mathrm{H}$ Peters for his constructive suggestions during the design of the study and Editage for editing the manuscript.

Contributors QW, MJ and YH designed the study. LL, NN, ZK, YL and YC collected data. QW, YH, NN, LL, LG and HS analysed the data. MJ, QW, YL, $\mathrm{YH}$ and $\mathrm{LL}$ drafted the manuscript. MJ, NN, YL and $\mathrm{QW}$ revised the manuscript. MJ, NN and YL contributed equally to this article.

Funding This study was funded by the Natural Science Foundation of China (Grant Number 71273002, 71203049, 71473064); New Century Excellent Talents in University, from the Ministry of Education, China (Grant No. 1252-NCET02); and Collaborative Innovation Centre of Social Risks Governance in Health.

\section{Competing interests None.}

Ethics approval Ethics approval for this study was granted by the Institutional Research Board of Harbin Medical University in August 2013.

Provenance and peer review Not commissioned; externally peer reviewed.

Data sharing statement No additional data are available.

Open Access This is an Open Access article distributed in accordance with the Creative Commons Attribution Non Commercial (CC BY-NC 4.0) license, which permits others to distribute, remix, adapt, build upon this work noncommercially, and license their derivative works on different terms, provided the original work is properly cited and the use is non-commercial. See: http:// creativecommons.org/licenses/by-nc/4.0/ 


\section{REFERENCES}

1. Hesketh T, Wu D, Mao L, et al. Violence against doctors in China BMJ 2012;345:e5730.

2. Workplace violence in the health sectors. Chinese Hospital Association, 2013:1-30.

3. Yassi A. Assault and abuse of health care workers in a large teaching hospital. CMAJ 1994;151:1273-9.

4. Merecz D, Rymaszewska J, Moscicka A, et al. Violence at the workplace - a questionnaire survey of nurses. Eur Psychiatry 2006;21:442-50.

5. Catlette M. A descriptive study of the perceptions of workplace violence and safety strategies of nurses working in level I trauma centers. J Emerg Nurs 2005;31:519-25.

6. AbuAIRub RF, Khalifa MF, Habbib MB. Workplace violence among Iraqi hospital nurses. J Nurs Scholarsh 2007;39:281-8.

7. Estryn-Behar M, van der Heijden B, Camerino D, et al. Violence risks in nursing-results from the European 'NEXT' Study. Occup Med (Lond) 2008;58:107-14.

8. Adib SM, Al-Shatti AK, Kamal S, et al. Violence against nurses in healthcare facilities in Kuwait. Int J Nurs Stud 2002;39:469-78.

9. Cai W, Deng L, Liu M, et al. Antecedents of medical workplace violence in South China. J Interpers Violence 2011;26:312-27.

10. Ito $\mathrm{H}$, Eisen SV, Sederer LI, et al. Factors affecting psychiatric nurses' intention to leave their current job. Psychiatr Serv 2001;52:232-4.

11. Kling RN, Yassi $A$, Smailes $E$, et al. Characterizing violence in health care in British Columbia. J Adv Nurs 2009;65:1655-63.

12. Jie L. New generations of Chinese doctors face crisis. Lancet 2012;379:1878

13. Hahn SZA, Needham IEA. Patient and visitor violence in general hospitals: a systematic review of the literature. Aggression Violent Behav 2008;13:431-41.

14. Ryan D, Maguire J. Aggression and violence-a problem in Irish accident and emergency departments. J Nurs Manag 2006;14:106-15.

15. Winstanley S, Whittington R. Violence in a general hospital: comparison of assailant and other assault-related factors on accident and emergency and inpatient wards. Acta Psychiatr Scand Supp/ 2002;106:144-7.

16. Nolan P, Dallender J, Soares J, et al. Violence in mental health care: the experiences of mental health nurses and psychiatrists. $J$ Adv Nurs 1999;30:934-41.

17. Alexander C, Fraser J. Occupational violence in an Australian healthcare setting: implications for managers. J Healthc Manag 2004;49:377-90; discussion 391-2.

18. Esmaeilpour M, Salsali M, Ahmadi F. Workplace violence against Iranian nurses working in emergency departments. Int Nurs Rev 2011;58:130-7

19. Gacki-Smith J, Juarez AM, Boyett L, et al. Violence against nurses working in US emergency departments. J Nurs Adm 2009;39:340-9.

20. Jackson D, Clare J, Mannix J. Who would want to be a nurse? Violence in the workplace-a factor in recruitment and retention. J Nurs Manag 2002;10:13-20.

21. May DD, Grubbs LM. The extent, nature, and precipitating factors of nurse assault among three groups of registered nurses in a regional medical center. J Emerg Nurs 2002;28:11-17.

22. Chen ZH, Wang SY. Psychiatric hospital and general hospital workplace violence study comparison. China Public Health 2004;20:1316-17 (in Chinese)

23. Chen $\mathrm{ZH}$, Wang SY, Jing $\mathrm{CX}$. Prevalence of workplace violence in staff of two hospitals in Guangzhou. Zhonghua Yu Fang Yi Xue Za Zhi 2003;37:358-60.

24. Ma WG, Li JP. Analyze hospital violence and countermeasures. $J$ Nurs Manag 2005;5:23-5 (in Chinese).

25. ILO/ICN/WHO/PSI. Framework guidelines for addressing workplace violence in health sector. 2002.
26. Chen WC, Hwu HG, Kung SM, et al. Prevalence and determinants of workplace violence of health care workers in a psychiatric hospita in Taiwan. J Occup Health 2008;50:288-93.

27. Frances A. Diagnostic and statistical manuals of mental disorders. 4th edn (DSM-IV). 1994.

28. Franz S, Zeh A, Schablon A, et al. Aggression and violence against health care workers in Germany-a cross sectional retrospective survey. BMC Health Serv Res 2010;10:51.

29. Gerberich SG, Church TR, McGovern PM, et al. An epidemiological study of the magnitude and consequences of work related violence: the Minnesota Nurses' Study. Occup Environ Med 2004;61:495-503.

30. Hahn S, Muller M, Needham I, et al. Factors associated with patient and visitor violence experienced by nurses in general hospitals in Switzerland: a cross-sectional survey. J Clin Nurs 2010;19:3535-46.

31. Zampieron A, Galeazzo M, Turra S, et al. Perceived aggression towards nurses: study in two Italian health institutions. J Clin Nurs 2010;19:2329-41.

32. Abbas MA, Fiala LA, Abdel RAG, et al. Epidemiology of workplace violence against nursing staff in Ismailia Governorate, Egypt. J Egypt Public Health Assoc 2010;85:29-43.

33. Algwaiz WM, Alghanim SA. Violence exposure among health care professionals in Saudi public hospitals. A preliminary investigation. Saudi Med J 2012;33:76-82.

34. Ayranci U, Yenilmez C, Balci Y, et al. Identification of violence in Turkish health care settings. J Interpers Violence 2006;21:276-96.

35. Kitaneh M, Hamdan M. Workplace violence against physician and nurses in Palestinian public hospitals: a cross-sectional study. BMC Health Serv Res 2012;12:469.

36. Shepherd J. Violence in health care: a practical guide to coping with violence and caring for victims. Oxford: Oxford University Press, 1996.

37. Hoff LA. Battered women: understanding, identification, and assessment. A psychosociocultural perspective, part 1. J Am Acad Nurse Pract 1992;4:148-55.

38. Camerino D, Estryn-Behar M, Conway PM, et al. Work-related factors and violence among nursing staff in the European NEXT study: a longitudinal cohort study. Int J Nurs Stud 2008;45:35-50.

39. Ferns T. Terminology, stereotypes and aggressive dynamics in the accident and emergency department. Accid Emerg Nurs 2005;13:238-46.

40. Hesketh KL, Duncan SM, Estabrooks CA, et al. Workplace violence in Alberta and British Columbia hospitals. Health Policy 2003;63:311-21.

41. Roche M, Diers D, Duffield C, et al. Violence toward nurses, the work environment, and patient outcomes. J Nurs Scholarsh 2010;42:13-22.

42. Magnavita N, Heponiemi T. Workplace violence against nursing students and nurses: an Italian experience. J Nurs Scholarsh 2011;43:203-10.

43. Shields M, Wilkins K. Factors related to on-the-job abuse of nurses by patients. Health Rep 2009;20:7-19.

44. Whittington R, Wykes T. An observational study of associations between nurse behaviour and violence in psychiatric hospitals. $J$ Psychiatr Ment Health Nurs 1994;1:85-92.

45. Li Y, Wu Q, Xu L, et al. Factors affecting catastrophic health expenditure and impoverishment from medical expenses in China: policy implications of universal health insurance. Bull World Health Organ 2012;90:664-71

46. Paola F, Malik T, Qureshi A. Violence against physicians. J Gen Intern Med 1994;9:503-6.

47. Blumenthal D, Hsiao W. Privatization and its discontents-the evolving Chinese health care system. N Engl J Med 2005;353:1165-70.

48. Carmi-Iluz T, Peleg R, Freud T, et al. Verbal and physical violence towards hospital- and community-based physicians in the Negev: an observational study. BMC Health Serv Res 2005;5:54.

49. [No authors listed]. Chinese doctors are under threat. Lancet 2010;376:657. 